\title{
Differential Contribution of Vestibular Evoked Myogenic Potentials for Diagnosis of Superior Semicircular Canal Dehiscence Syndrome
}

\author{
Esmeralda Rocío Martín ${ }^{1,3}$, Lorena Vega Zelaya ${ }^{1,3}$, Laura López Viñas ${ }^{1}$, Salvador Delis Gómez ${ }^{1}$, Yvonne López \\ Castanier $^{2}$ and Jesús Pastor ${ }^{1,3 *}$
}

${ }^{1}$ Clinical Neurophysiology, Hospital Universitario La Princesa, Spain

${ }^{2}$ Departament of Otolaryngology, Hospital Universitario La Princesa, Spain

${ }^{3}$ Instituto de Investigación Sanitaria Princesa, Spain

*Corresponding author: Jesús Pastor, Clinical Neurophysiology. Hospital Universitario La Princesa C/Diego de León, Madrid, Spain

\begin{abstract}
Introduction: Superior semicircular canal dehiscence syndrome (SSCDS) is described as a disorder of the inner ear denoted by the absence of a bony covering, causing vestibular and auditory symptomatology. The vestibular evoked myogenic potentials (VEMPs) provide information regarding the vestibular function, which is useful in the diagnosis of vestibular disorders. Our aim is to assess the differential role of ocular VEMP (oVEMP) and cervical VEMP (cVEMP).
\end{abstract}

Methods: oVEMPs and cVEMPs were collected from four male and five female ( $64.5 \pm 3.6$ years old) with SSCDS validated by computerized axial tomography between 2017 and 2019. The neurophysiological assessment included the calculation of latency and amplitude of both the pathological ear (PE) and the healthy ear (HE) and the asymmetry ratio (AR) of both ears. A control group comprising 14 people without vestibular pathology and similar age was utilized.

Results: The control group fitted well to the Gaussian distribution. The most persistent symptom was vertigo, followed by hearing loss. One patient had bilateral SSCDS. The latency was higher for cVEMPs at PE but was not disparate for oVEMP latency. In contrast, amplitude was higher at PE than at HE for both tests. Nonetheless, AR was $>34 \%$ in all oVEMPs, while there were only in two of eight cases for cVEMPs.

Conclusion: Though cVEMP abnormalities in amplitude may help to suspect the pathology, oVEMP is the most sensitive and strong test for the diagnosis of SSCDS. This technique is a rapid, reliable, inexpensive test without side effects and thus has a very vital use as a screening and follow-up test in SSCDS.

Keywords: cVEMP; Clinical Neurophysiology; Hearing loss; Nystagmus; oVEMPs; Vertigo; Vestibular disorders

Abbreviations: AR: Asymmetry Ratio; CT = Computed Tomography; IOM: Inferior Oblique Muscle; cVEMP: Cervical Vestibular Evoked Myogenic Potentials; HE: Healthy Ear; nHL: Normal Hearing Level; oVEMP: Ocular Vestibular Evoked Myogenic Potentials; PE: Pathological Ear; SCM: Sternocleidomastoid Muscle; SSCDS: Superior Semicircular Canal Dehiscence Syndrome; VEMP: Vestibular Evoked Myogenic Potentials

\section{Introduction}

Superior semicircular canal dehiscence syndrome (SSCDS) is described presently as a disorder of the inner ear [1], denoted by the absence of a bony covering of this canal [2]. This acts as a "third window" anomaly, modifying the physiological functions of the inner ear, which generate an abnormal transmission of vibration to the vestibular system, responsible for the clinical symptomatology, such as vertigo, nystagmus, oscillopsia, and disequilibrium prompted by loud sounds (Tullio phenomenon) $[3,4]$. Furthermore, the Valsalva maneuver stimulates shifts in the pressure of the middle or intracranial ear because of pressure changes in the 
external auditory canal (Hennebert sign). This medical entity may also emerge in various other several clinical expressions, such as conductive hearing loss with a normal stapedial reflex [5], autophony, and hyperacusis with increased sensitivity for bone conduction, otic fullness [6], and pulsatile tinnitus [7]. The gold standard to validate the presence of the superior semicircular canal dehiscence (SSCDS) is high-resolution computed tomography (CT) of the temporal bone [8,9]. Nevertheless, neurophysiological studies to evaluate vestibular function are also noted [10]. Vestibular evoked myogenic potentials (VEMPs) have been proven useful in the diagnosis of vestibular disorders. However, there has not been too much attention to the SSCDS. VEMPs are time-locked muscular responses prompted by an auditory stimulus and give indispensable information regarding the otolithic organs (utricle and saccule), nerves, and vestibular nuclei (Figure 1) [11,12]. Ocular vestibular evoked myogenic potentials (oVEMPs) are ascending and excitatory utriculo-sacular responses that allow us to assess the integrity of the vestibular-ocular pathways $[13,14]$. On the other hand, cervical vestibular evoked myogenic potentials (cVEMPs) are descending and inhibitory saculocolic responses that give information regarding the vestibulospinal pathways [15]. The principal objective of this work was to evaluate the various roles of both types of VEMPs in the SSCDS. To give a useful as well as objective information, findings have been compared with a control group of people without vestibular pathology.

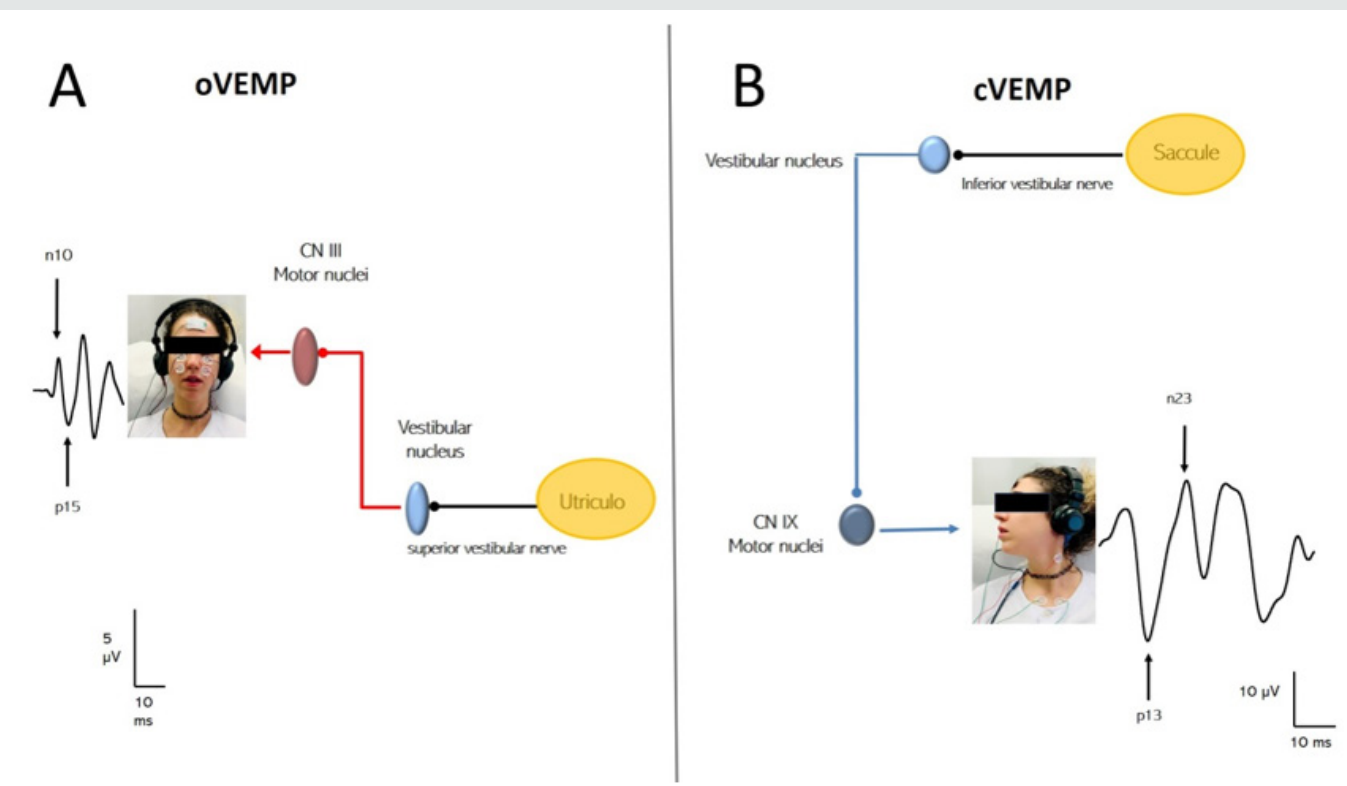

Figure 1: Neural pathways involved in VEMPs. The utricle-sacular pathway (red), which is valued with oVEMPs, is an excitatory and cross-pathway. The sacculal-colic pathway (blue) is an inhibitory and direct response, which is studied by cVEMPs.

\section{Materials and Methods}

\section{Subjects}

The study involved nine patients (four male and five female) with vestibular pathology, referred by an otolaryngologist that has a specialization in vestibular disorders (YLC), between 2017 and
2020 (Table 1). All of them had a diagnosis of SSCDS validated by CT. Furthermore, we conducted VEMPs among them and in a control group of 14 volunteers who had no vestibular pathology. The ethics committee of the Hospital Universitario La Princesa approved this study.

Table 1: Demographic and clinical features of patients.

\begin{tabular}{|c|c|c|c|}
\hline Patients & Age & Gender & Clinical symptoms \\
\hline 1 & 70 & M & Vertigo $^{a} /$ Hearing loss \\
\hline 2 & 76 & M & Vertigo/Disequilibrium/Hearing loss/Tinnitus \\
\hline 3 & 52 & M & Vertigo ${ }^{a} /$ Hearing loss/Tinnitus \\
\hline 4 & 71 & $\mathrm{~F}$ & Vertigo $^{\mathrm{a}} /$ Disequilibrium/OF \\
\hline 5 & 47 & $\mathrm{~F}$ & Vertigo $^{c} /$ Disequilibrium/Hearing loss /OF \\
\hline 6 & 67 & M & Vertigo/Disequilibrium/Tinnitus /Autophony \\
\hline 7 & 60 & $\mathrm{~F}$ & Vertigo/Hearing loss/OF \\
\hline
\end{tabular}




\begin{tabular}{|c|c|c|c|}
\hline 8 & 57 & F & Vertigo/Disequilibrium/Hearing loss \\
\hline 9 & 76 & F & Vertigo $^{\mathrm{b}} /$ Hearing loss/Nistagmus \\
\hline
\end{tabular}

F: Female; M: Male; OF: Otic fullness. a: Caused by changes in the pressure; b: Caused by loud sounds; c: Espontáneous and caused by changes in the pressure.

\section{Neurophysiological tests}

VEMPs were obtained by means of a four-channel Neurosoft ${ }^{\circledR}$ system (Ivanovo, Russia) with specific software. Myogenic responses were procured via disposable surface electrodes $\left(\mathrm{Ambu}^{\circledR}\right.$, Ballerup, Denmark). Settings for oVEMP recording include the placement of the active electrode underneath the orbitary area, near the inferior oblique muscle (IOM), and $2 \mathrm{~cm}$ under the reference electrode. The ground electrode was put on the forehead (Figure 1). The patient was then instructed to stare ipsilateral upside to the auditory stimulus, the chin remaining straightforward. Responses were acquired in a bilateral manner [16]. Settings from cVEMPs include the placement of the active electrode in the middle of the ipsilateral sternocleidomastoid muscle (SCM) and the reference electrode at the upper part of the sternum (belly-tendon placement). During the test, the patient stayed in a supine position with the head lifted at $30^{\circ}$ above the horizontal plane and rotated to the stimulated ear's contralateral side (Figure 1). This response is because of the transient inhibition of muscle contraction [17-19]. Monaural acoustic stimulation was conducted via the headphones by means of $500 \mathrm{~Hz}$ bursts ( $100 \mathrm{~dB} \mathrm{nHL}$ ) and 6-8 ms duration at $5 \mathrm{~Hz}$ frequency. Masking white noise in the contralateral ear was utilized $(-40 \mathrm{~dB}$ $\mathrm{nHL}$ ). The bandwidth was $20 \mathrm{~Hz}-2 \mathrm{kHz}$, notch on (50 Hz). Two hundred stimuli were delivered, and signals were then averaged with a sampling rate of $20 \mathrm{kHz}$. The electrode resistivities were kept below $5 \mathrm{k} \Omega$. At least two rounds for each test were conducted, with no pre-stimulus normalization. For oVEMPs, the latency was defined as the first negative deflection (n10), and, for cVEMPs, it was the first positive deflection ( $\mathrm{p} 13$ ), where $\mathrm{n}$ is negative (upward deflection) and $\mathrm{p}$ is positive (downward deflection). The numbers refer to the time in ms. The amplitude (in $\mu \mathrm{V}$ ) was calculated to be between p13-n23 for oVEMPs and cVEMPs, respectively. We also have measured the asymmetry between the amplitudes, wherein usually a significant symmetry is greater than 34\% [20]. The asymmetry ratio (AR) was measured with the use of the following formula:

$$
A R=\frac{V E M P 1-V E M P 2}{V E M P 1+V E M P 2} \times 100
$$

Where VEMP1 refers to the higher potential and VEMP2 to the lower one.

Pathological findings have been defined in accordance to a double criteria:

a) Own standard control tables acquired from people with no pathology and, also, as an additional control system, as seen in published tables [21,22], and

b) Furthermore the AR. Fiducial limits have been defined as mean \pm 2.5 standard error of the mean (SEM) for our data and mean \pm 2.5 standard error for published data.

Imaging tests were conducted before VEMPs in five patients, and SSCDS has been validated using both tests. In the remaining cases, the pathological side was determined with VEMPs, and the diagnosis of SSCDS was then validated with the imaging test. We conducted an evaluation of the data with the use of responses from the pathological ear (PE) and the healthy ear (HE).

\section{Statistical analysis}

For the patient's group, we categorized the sample into two groups:

a) The pathological ear (PE) and

b) The healthy ear (HE).

For the control group, both ears were considered to be nonpathological. Statistical comparisons between groups were conducted with the use of Student's t-test or analysis of variance (ANOVA) for data with normal distribution. Normality was assessed with the use of the Kolmogorov-Smirnov test. Mann-Whitney rank sum test or ANOVA on ranks was utilized when the data have no normal distribution. Sigma Stat ${ }^{\circledast} 3.5$ software (Point Richmond, CA, USA) was employed for statistical analysis. The significance level was set at $p=0.05$. Results are indicated as mean \pm SEM, except where otherwise stipulated.

\section{Results}

\section{Control group}

We have obtained the control values from people with no vestibular pathology which are picked up from our environment. The mean age was $54.3 \pm 3.9$ years. Results are outlined in Table 2. As expected, the results from our control group were somewhat similar to the ones published. However, there was a slight increase in latency and decrease in amplitude for cVEMP, although in both cases no statistical significance was noted (Mann-Whitney rank test). It is interesting to note that median and mean values are very similar for most of the variables, insinuating that normality can be presumed and the common test behaves strongly. We evaluated the AR from our group as well. Results are indicated at the bottom row of Table 2. SD instead of SEM has been utilized to increase the fiducial boundaries. We have obtained an upper limit of almost $20 \%$. 
Table 2: Descriptive statistics for the control group.

\begin{tabular}{|c|c|c|c|c|c|}
\hline & Mean & SEM & Median & IP25-75 & Fiducial boundaries \\
\hline \multicolumn{6}{|c|}{ cVEMP } \\
\hline \multicolumn{6}{|c|}{ Left Ear } \\
\hline Latency p13 (ms) & 14.76 & 0.35 & 14.4 & $13.9-15.90$ & $13.88-15.63$ \\
\hline Latency n23 (ms) & 21.42 & 0.31 & 21.65 & $20.30-22.10$ & $20.64-22.19$ \\
\hline Amplitude $(\mu \mathrm{V})$ & 67.35 & 6.74 & 67 & $45.50-83.00$ & $50.50-84.20$ \\
\hline \multicolumn{6}{|c|}{ Right Ear } \\
\hline Latency p13 (ms) & 14.46 & 0.3 & 14.35 & $13.40-15.50$ & $13.71-15.21$ \\
\hline Latency n23 (ms) & 21.17 & 0.45 & 21.03 & $20.10-22.40$ & $20.04-22.29$ \\
\hline Amplitude $(\mu \mathrm{V})$ & 68.29 & 6.34 & 60 & $52.60-82.75$ & $52.44-84.14$ \\
\hline \multicolumn{6}{|c|}{ oVEMP } \\
\hline \multicolumn{6}{|c|}{ Left Ear } \\
\hline Latency n10 (ms) & 10.27 & 0.19 & 10.1 & $9.95-10.40$ & $9.79-10.74$ \\
\hline Latency p15 (ms) & 14.62 & 0.3 & 14.5 & $14.10-15.00$ & $13.87-15.37$ \\
\hline Amplitude $(\mu \mathrm{V})$ & 5.32 & 0.54 & 5.85 & $3.00-6.90$ & $3.97-6.67$ \\
\hline \multicolumn{6}{|c|}{ Right Ear } \\
\hline Latency n10 (ms) & 10.26 & 0.18 & 10.01 & $9.90-10.40$ & $9.81-10.71$ \\
\hline Latency p15 (ms) & 14.74 & 0.37 & 14.92 & $14.35-15.75$ & $13.81-15.66$ \\
\hline Amplitude $(\mu \mathrm{V})$ & 5.35 & 0.44 & 5.9 & $3.80-6.80$ & $4.25-6.45$ \\
\hline Asymmetry Ratio (AR) & 7.05 & $5.01^{*}$ & 6.3 & $1.28-7.79$ & $<19.58^{* *}$ \\
\hline
\end{tabular}

IP25-75 Interpercentile range 25-75; * Correspond to SD; ** Upper limit of asymmetry ratio.

\section{Patients group}

The mean age was $64.5 \pm 3.9$ years, which is no different from the control group (Mann-Whitney rank test). CT of temporal bone validated the presence of SSCDS in all the patients. One of the patients was diagnosed with bilateral SSCDS (see subsequent text).

The most common clinical manifestations were as follows:

a) Vertigo in all patients due to changes in the pressure among four of them and due to exposure to an intense sound in one

b) Conductive hearing loss in seven patients and chronic disequilibrium in five patients.

We have pooled the neurophysiological findings from ten responses for PE (both ears picked up from the bilateral SSCDS) and eight responses for HE. Latency and amplitude values in oVEMPs and cVEMPs of both ears from patients with SSCDS are outlined in Table 3. Latencies overall considered either from PE or HE were between normal limits. In the case of oVEMPs, no differences were noted between both groups $(9.8 \pm 0.2 / 10.1 \pm 0.4 \mathrm{~ms}$ for PE and HE, respectively; n.s paired Student t-test). Nonetheless, in the case of cVEMPs, the mean latency for PE was higher than for HE (13.7 $\pm 0.7 / 12.6 \pm 0.8 \mathrm{~ms}, \mathrm{p}=0.023$ paired Student t-test). However, amplitudes were always higher for PE, such as for oVEMPs (41.5 $\pm 8.3 / 6.4 \pm 1.2 \mu \mathrm{V}$ for PE/HE, $\mathrm{p}<0.005$ paired Student-t test) and cVEMPs $(148.8 \pm 39.4 / 87.2 \pm 28.0 \mu \mathrm{V}, \mathrm{p}=0.029$, paired Student- $t$ test). PE amplitudes were higher for oVEMP ( $p<0.001$, MannWhitney rank test) and cVEMP ( $p=0.045$, Mann-Whitney rank test) as well, compared to the control group, but values for HE were between the control limits. See Figure 2 for a typical example of unilateral SSCDS. AR was greater than $34 \%$ in all cases $(8 / 8)$ for oVEMPs (pooled $62.8 \pm 6.2 \%$ ) but only $2 / 8$ for cVEMPs (pooled $26.9 \pm 10.7 \%$ ). AR was $<34 \%$ in the case of the patient with bilateral SSCDS (12.2\% for oVEMP and $32.3 \%$ for cVEMP). Thus, the sensitivity for oVEMPs was $100 \%$, whereas the sensitivity for cVEMPs was only $25 \%$. Figure 2 shows an example of a patient with left SSCDS. We evaluated the association between latencies and amplitudes using the least-squares fit, for either PE or HE, but no correlation was found.

Table 3: Neurophysiological features oVEMPs and cVEMPs in patients with SSCDS.

\begin{tabular}{|c|c|c|c|c|c|c|c|c|}
\hline \multirow{3}{*}{ S. No } & \multicolumn{4}{|c|}{ Healthy Ear } & \multicolumn{4}{|c|}{ Pathological Ear } \\
\hline & \multicolumn{2}{|c|}{ oVEMP } & \multicolumn{2}{|c|}{ cVEMP } & \multicolumn{2}{|c|}{ oVEMP } & \multicolumn{2}{|c|}{ cVEMP } \\
\hline & $\begin{array}{l}\text { Latency n10 } \\
(\mathrm{ms})\end{array}$ & $\begin{array}{c}\text { Amplitude } \\
\text { n10-p15 }(\mu \mathrm{V})\end{array}$ & $\begin{array}{l}\text { Latency p13 } \\
\text { (ms) }\end{array}$ & $\begin{array}{c}\text { Amplitude } \\
\text { p13-n23 }(\mu V)\end{array}$ & $\begin{array}{l}\text { Latency n10 } \\
\text { (ms) }\end{array}$ & $\begin{array}{c}\text { Amplitude } \\
\text { n10-p15 }(\mu V)\end{array}$ & $\begin{array}{l}\text { Latency p13 } \\
\text { (ms) }\end{array}$ & $\begin{array}{c}\text { Amplitude } \\
\text { p13-n23 }(\mu \mathrm{V})\end{array}$ \\
\hline 1 & 10.4 & 13.4 & 13.7 & 190 & 9.5 & 40 & 15.9 & 334 \\
\hline 2 & 11.4 & 6 & 15.2 & 26.8 & 10.9 & 35.5 & 15.4 & 59.8 \\
\hline 3 & 10.6 & 3.4 & 16 & 50 & 10.1 & 68.8 & 16.2 & 222 \\
\hline
\end{tabular}

Citation: Esmeralda Rocío M, Lorena Vega Z, Laura López V, Salvador Delis G, Yvonne López C, Jesús P. Differential Contribution of Vestibular Evoked Myogenic Potentials for Diagnosis of Superior Semicircular Canal Dehiscence Syndrome. Sch J Oto 4(4)-2020. SJ0. MS.ID.000193. DOI: $10.32474 /$ SJ0.2020.04.000193. 


\begin{tabular}{|c|c|c|c|c|c|c|c|c|}
\hline 4 & 10.5 & 3.9 & 11 & 57.3 & 9.8 & 80.2 & 11.6 & 65.2 \\
\hline 5 & 9.1 & 8.9 & 10.3 & 58.4 & 10.3 & 27.1 & 12.9 & 130 \\
\hline 6 & 10.8 & 4.9 & 11 & 80.5 & 10.5 & 18.7 & 11.8 & 118 \\
\hline 7 & 8 & 7.1 & 11.2 & 229 & 8.1 & 49.1 & 12.3 & 254 \\
\hline 8 & 9.7 & 3.9 & 12.5 & 5.9 & 9.9 & 12.6 & 12.6 & 7.18 \\
\hline 9 & - & - & - & - & 9.5 & 51.2 & 15.6 & 215 \\
\hline 10 & - & - & - & - & 10 & 40.1 & 13.4 & 110 \\
\hline
\end{tabular}

oVEMP: ocular vestibular evoked miogenic potential; cVEMP: cervical vestibular evoked miogenic potential; HE: healthy ear; PE: pathological ear.

A1

Left stimuli

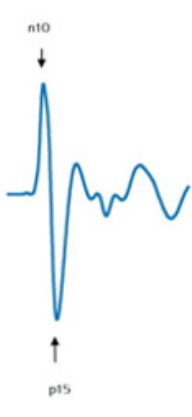

IOM contralateral
OVEMP

Right stimuli

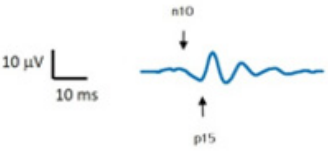

IOM contralateral
A2

Left stimuli
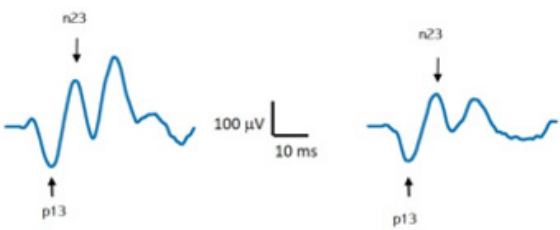

SCM ipsilateral $\quad 50 \mu v \bigsqcup_{10 \mathrm{~ms}}$
Right stimuli

Figure 2: Usual findings VEMPs in patient with left SSCDS. A1) Bilateral oVEMPs showing increase in amplitude at contralateral IOM, after left ear stimulation. A2) Bilateral cVEMPs showing increase at ipsilateral SCM response, after left ear stimulation.

Finally, a more detailed bilateral SSDCS case was shown here. The patient was a 77-year-old woman referred for sudden spontaneous disequilibrium prompted by a loud noise and progressive bilateral pseudo-conductive hearing loss predominantly in the left ear. VEMPs demonstrated a remarkable increased amplitude in the responses from both oVEMPs as regards the normal values from the standardized tables. An amplitude of $51.2 \mu \mathrm{V}$ was recorded in the right ear, and an amplitude of $40.1 \mu \mathrm{V}$ was recorded in the left ear. Both values were pathological, proposing the presence of SSCDS. This fact was validated by CT conducted a posteriori.

\section{Discussion}

The principal aim of our study was to evaluate the specific role for oVEMP and cVEMP in the diagnosis of SSCDS. We have shown that even though cVEMP anomalies in amplitude may help to suspect the pathology, oVEMP is the most sensitive and strong test for the diagnosis of this syndrome. SSCDS could be due to the modification of fluid dynamics, where dehiscence would act as a "third window" in the inner ear, thus reducing the resistivity of the vestibular system and the resistance to the transmission of pressure and sound $[1,3]$. Because of this, the high intensity of the movement of the perilymph would generate a greater stimulation of the receptors of the vestibular system, leading to an increase in the amplitude of the response [24]. Presently, there are no amplitude or latency values capable of defining SSCDS. Usually a decrease in amplitude is a commonly accepted criterion in the neurophysiological test for one to say that it is pathologic. However, in the case of a disturbance of the vestibular system, an abnormally large potential would show the presence of a mobile "third window" in the labyrinth, as in SSCDS. Increased latency from VEMPs is not common, and it is usually correlated with conduction abnormalities in the central nervous system, as in the case of patients impacted with multiple sclerosis (ME) [11,23]. An own control group has been utilized from the same population as patients. This is a recommendation in most of the neurophysiological tests but seldom conducted. Values for latencies and amplitudes are similar to those found in literature $[13,14]$, which is not unexpected. What is slightly more surprising was the observation that most of the variables fitted well to a Gaussian distribution. We also determined that the upper limit for AR is lower than the commonly accepted $34 \%$.

Nonetheless, this criterion to define pathology has not been used since we need a greater number of people to be more confident. There are various studies that describe the decrease of the threshold and the increase in the amplitude of VEMPs [25-27] or the use of high-frequency stimulation to elicit the n10 component of oVEMPs [28]. However, few studies have investigated the diagnostic value 
of the increased amplitude of the oVEMPs and the asymmetry ratio in the SSCDS $[29,30]$. It has been shown that a decreased threshold provides diagnostic value, but the determination of the threshold may be uncomfortable for the patient [30]. The recording and measuring of oVEMPs need less time and effort than measuring the thresholds for cVEMPs since, in the latter, the patient should be kept in an uncomfortable position more time than for oVEMP. It is essential to keep in mind then for these patients that an intense sound can trigger vestibular symptoms; thus, it is advisable to minimize the duration of the study. With this study, we can conclude that the increase in the amplitude of oVEMPs has a high diagnostic value in the SSCDS. However, cVEMPs have a lower sensitivity, and, therefore, testing them should not be done in some cases, decreasing the time of the test but maintaining the same efficacy.

The VEMPs are well tolerated by the patient, fast, inexpensive, and without side effects, so it can be considered an outstanding screening test for SSCDS, and, besides, these tests are potentially useful for objective follow-up following the treatment. The chief limitation of our study is the number of patients; however, the results are strong and therefore open up the possibility of extending the spectrum of utility of these potentials for various neuro-otology disorders as well as monitoring the evolution of SSCDS.

\section{Conflict of Interests}

The authors have no conflict of interest.

\section{Funding}

This work was partially financed (L V-Z and JP) by a grant from the Ministerio de Sanidad FIS PI17/02193 and was partially supported by FEDER (Fonds Europeen de Developpement Economique etc. Regional).

\section{References}

1. Minor LB, Solomon D, Zinreich JS, Zee DS (1998) Sound and/or pressureinduced vertigo due to bone dehiscence of superior semicircular canal. Arch Otolaryngol Head Neck Surg 124(3): 249-258.

2. Gianoli GJ (2001) Deficiency of the superior semicircular canal. Curr Opin Otolaryngol Head and Neck Surg 9: 336-341.

3. Minor LB, Cremer PD, Carey JP, Della Santina CC, Streubel SO, et al. (2001) Symptoms and signs in superior canal dehiscence syndrome. Ann N Y Acad Sci 942: 259-273.

4. Watson SRD, Halmagy GM, Colebatch JG (2000) Vestibular hypersensitivity to sound (Tullio Phenomenon): Structural and functional assessment. Neurology 54(3): 722-728.

5. Mikulec AA, McKenna MJ, Ramsey MJ, et al. (2004) Superior semicircular canal dehiscence presenting as conductive hearing loss without vertigo. Otol Neurotol 25(2): 121-129.

6. Mong A, Loevner LA, Solomon D, Bigelow DC (1999) Sound and pressureinduced vertigo associated with dehiscence of the roof of the superior semicircular canal. Am J Neurorradiol 20: 1973-1975.

7. Spasic M, Trang A, Chung LK, Ung N, Thill K, et al. (2015) Clinical Characteristics of Posterior and Lateral Semicircular Canal Dehiscence. J Neurol Surg B Skull Base 76(6): 421-425.
8. Marlien EF, Leena MN, Joshua BH, Kristina VS, Andrew AL, Windsor MA, et al. (2014) Superior Canal Dehiscence Length and Location Influences Clinical Presentation and Audiometric and Cervical Vestibular-Evoked Myogenic Potential Testing. Audiol Neurootol 19: 97-105.

9. Gartrell CR, Gentry RL, Kennedy AT, Gubbels PS (2014) Radiographic Features of Superior Semicircular Canal Dehiscence in the Setting of Chronic Ear Disease. Otol Neurotol 35(1): 91-96.

10. Shin BS, Oh SY, Kim JS, Kim TW, Seo MW, et al. (2012) Cervical and ocular vestibular-evoked myogenic potentials in acute vestibular neuritis. Clin Neurophysiol 123: 369-375.

11. Benito Orejas JI (2016) Utilidad clínica de los potenciales evocados miogénicos vestibulares. Rev ORL 7: 223-235.

12. Kantner C, Gürkov R (2012) Characteristics and clinical applications of ocular vestibular evoked myogenic potentials. Hear Res 294: 55-63.

13. Rosengren SM, Aw ST, Halmagyi GM, Todd NP, Colebatch JG (2008) Ocular vestibular evoked myogenic potentials in superior canal dehiscence. J Neurol Neurosurg Psychiatry 79: 559-568.

14.Zuniga MG, Janky KL, Nguyen KD, Welgampola MS, Carey JP (2013) Ocular versus cervical VEMPs in the diagnosis of superior semicircular canal dehiscence syndrome. Otol Neurotol 34(1): 121-126.

15. Colebatch JG, Halmagyi GM (1992) Vestibular evoked potentials in human neck muscles before and after unilateral vestibular deafferentation. Neurology 42: 1635-1636.

16. Weber KP, Rosengren SM (2015) Clinical utility of ocular vestibularevoked myogenic potentials (oVEMPs). Curr Neurol Neurosci Rep 15(5): 22.

17. Papathanasiou ES, Murofushi T, Akin FW, Colebatch JG (2014) International guidelines for the clinical application of cervical vestibular evoked myogenic potentials: an expert consensus report. Clin Neurophysiol 125(4): 658-666.

18. Colebatch JG, Rothwell JC (2004) Motor unit excitability changes mediating vestibulocollic reflexes in the sternocleidomastoid muscle. Clin Neurophysiol 115: 2567-2573.

19. Sheykholeslami K, Murofushi T, Kaga K (2001) The effect of sternocleidomastoid electrode location on vestibular evoked myogenic potential. Auris Nasus Larynx 28: 41-43.

20. Murofushi T, Kaga K (2009) Vestibular Evoked Myogenic Potential. Its basics and clinical applications. Tokyo, Springer pp. 28-29.

21. Silva TR, Resende LM, Santos MA (2016) Ocular and cervical vestibular evoked myogenic potential simultaneous in normal individuals. CoDAS 28: $34-40$.

22. Blakley BW; Wong V (2015) Normal Values for Cervical Vestibular Evoked Myogenic Potentials Otol Neurotol 36: 1069-1073.

23. Felipe L, Carvalho SAS, Cunha LCM, Santos MAR, Peixoto MAL, et al. (2009) Hallazgos de potenciales vestibulares miogénicos evocados en la esclerosis múltiple Rev Neurol 48: 284-286.

24. Mercado M, Víctor MM (2016) Síndrome de dehiscencia del canal semicircular superior: A propósito de un caso. Revista de otorrinolaringología y cirugía de cabeza y cuello 76: 55-62.

25. Hunter JB, Patel NS, OConnell BP, Carlson ML, Shepard NT, et al. (2017) Cervical and Ocular VEMP Testing in Diagnosing Superior Semicircular Canal Dehiscence. Otolaryngology-Head and Neck Surgery 156(5): 917-923.

26. Govender S, Fernando T, Dennis DL, Welgampola MS, Colebatch JG (2016) Properties of $500 \mathrm{~Hz}$ air- and bone-conducted vestibular evoked myogenic potentials (VEMPs) in superior canal dehiscence. Clin Neurophysiol 127(6): 2522-2531.

27. Janky KL, Nguyen KD, Welgampola M, Zuniga MG, Carey JP (2013) Airconducted oVEMPs provide the best separation between intact and superior canal dehiscent labyrinths. Otol Neurotol 34(1): 127-134. 
28. Lin K, Lahey R, Beckley R, Bojrab D, Wilkerson B, Johnson E et al. (2019) Validating the Utility of High Frequency Ocular Vestibular Evoked Myogenic Potential Testing in the Diagnosis of Superior Semicircular Canal Dehiscence. Otol Neurotol 40(10): 1353-1358.

29. Rosengren SM, Aw ST, Halmagyi GM, Todd NP, Colebatch JG (2008) Ocular vestibular evoked myogenic potentials in superior canal dehiscence. J Neurol Neurosurg Psychiatry 79: 559-568.
30. Zuniga MG, Janky KL, Nguyen KD, Welgampola MS, Carey JP (2013) Ocular versus cervical VEMPs in the diagnosis of superior semicircular canal dehiscence syndrome. Otol Neurotol 34: 121-126.

\section{(c) (i) \\ This work is licensed under Creative Commons Attribution 4.0 License}

To Submit Your Article Click Here:

Submit Article

DOI: $10.32474 /$ SJO.2020.04.000193

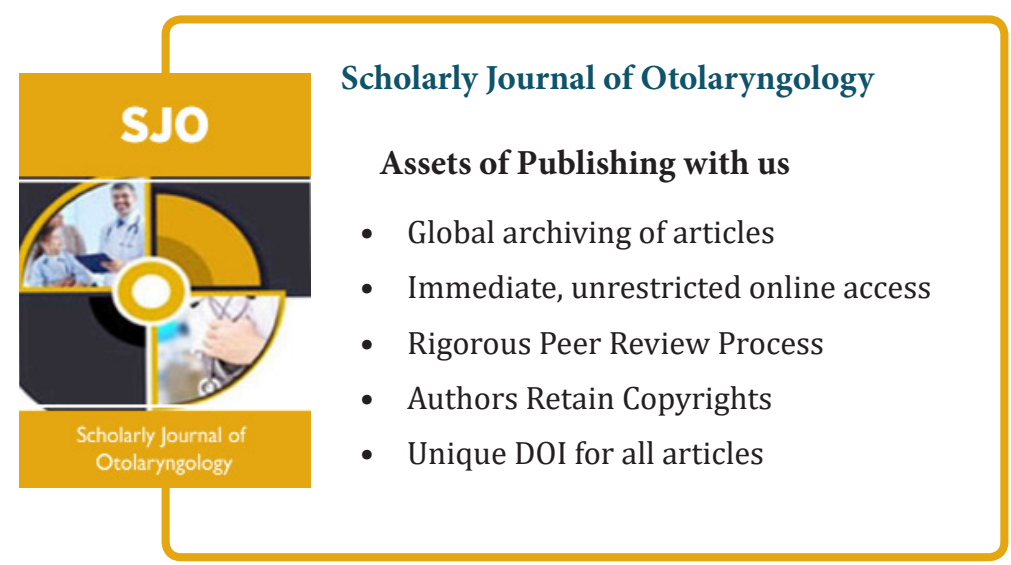

